\section{ZOOPLANKTON ECOLOGY}

\section{Preface}

\author{
Jiang-Shiou Hwang $\cdot$ Koen Martens
}

Published online: 4 March 2011

(C) Springer Science+Business Media B.V. 2011

The conference on "Zooplankton behavior, ecology and aquaculture" was held at the National Taiwan Ocean University (NTOU), Keelung, Taiwan, from October 6th to 8th, 2009. Zooplankton holds a key position in many aquatic environments, especially in oceanic systems. Among the zooplankton, copepods not only show a tremendous adaptive radiation, diversity, high abundance, and biomass, but also a remarkably extensive distribution. As long as water is present, traces of copepods can be found. Hence, copepods have frequently been described as the insects of the ocean. Copepods make up more than $70 \%$ of overall zooplankton abundances. Thus, scientists in many countries around the world are making special efforts to study copepod, and other zooplankton, ecology.

The conference has invited distinguished scholars in the fields of zooplankton behavior, ecology, and aquaculture. 146 participants came from 15 countries: America (USA), Belize, Denmark, France, Germany,

Guest editors: J.-S. Hwang and K. Martens / Zooplankton Behavior and Ecology

J.-S. Hwang ( $\square)$

Institute of Marine Biology, National Taiwan Ocean

University, Keelung 202-24, Taiwan

e-mail: Jshwang@mail.ntou.edu.tw

K. Martens

Royal Belgian Institute of Natural Sciences, Brussels, Belgium
Hong Kong, India, Italy, Mexico, Russia, Senegal, Spain, Taiwan, Thailand, Tunisia (by nationality in alphabetical order) and presented 46 oral and 28 poster communications. Whereas the scientific program was thus extensive, the goal of academic exchange between foreign and Taiwanese scientists was also achieved through interactions and discussions during the meeting, as well as during the post meeting excursion to several cultural and scenic locations from central to northern Taiwan.

The present collection of papers results from this meeting and provides a taste of the wide variety of topics that were presented. The guest editors thank the reviewers that have greatly contributed to the quality of the present proceedings. The chair of the meeting acknowledges financial support from the National Science Council of Taiwan and from the Center of Excellence for Marine Bioenvironment and Biotechnology (NTOU, Taiwan). 